\title{
CubeSat Development for Lightning Flashes Detection: RaioSat Project
}

\author{
Antonio Cassiano Julio Filho ${ }^{1, \star} \mathbb{D}$, Auro Tikami ${ }^{\mathbb{D}}$, Elaine de Souza Ferreira de Paula² $\mathbb{D}$, Jhonathan \\ Murcia Piñeros ${ }^{3} \mathbb{D}$, George Favale Fernandes ${ }^{4} \mathbb{D}$, Lázaro Aparecido Pires Camargo ${ }^{1} \mathbb{D}$, Carlos Alberto \\ Monteiro Barbosa dos Santos ${ }^{[} \mathbb{D}$, Walter Abrahão dos Santos ${ }^{1} \mathbb{D}$, Kleber Pinheiro Naccarato ${ }^{6}$ [D
}

1. Instituto Nacional de Pesquisas Espaciais - Coordenação Geral de Engenharia, Tecnologia e Ciência Espaciais - Divisão de Pequenos Satélites - São José dos Campo/SP - Brazil. 2. Instituto Nacional de Pesquisas Espaciais - Coordenação Geral de Engenharia, Tecnologia e Ciência Espaciais - Divisão de Eletrônica Espacial e Computação - São José dos Campos/SP - Brazil. 3. Universidade Federal de São Paulo - Instituto de Ciência e Tecnologia - Departamento de Matemática Pura e Aplicada - São José dos Campos/SP - Brazil. 4. Vírus Industrial Aerospace - Departamento de Pesquisa e Desenvolvimento - CubeSat Lab - São Paulo/SP - Brazil. 5. Instituto Nacional de Pesquisas Espaciais Coordenação Geral de Engenharia, Tecnologia e Ciência Espaciais - Serviço de Garantia do Produto - São José dos Campos/SP - Brazil. 6. Instituto Nacional de Pesquisas Espaciais - Coordenação Geral das Ciências da Terra - Divisão de Adaptação e Vulnerabilidades - São José dos Campos/SP - Brazil.

*Correspondence author: cassiano.filho@inpe.br

\begin{abstract}
Annually, severe weather phenomena are responsible for tens of thousands of deaths and tens of billions of dollars of damage around the world. In Brazil, unlike other hydrometeorological events, severe atmospheric events are random and, therefore, do not have a sociospatial pattern. Because of that, there is a significant motivation to improve the prediction techniques for this kind of events, using high resolution numerical models. A large amount of high-quality observational data is required, including lightning data in a very short-range. In addition, the detection of lightning flashes produced by storms is important for a wide variety of applications and in some areas of scientific research, which include the understanding of the human action on the climate and how the climate change can affect the behavior of storms in long range. One method to monitor the lightning flashes is the implementation of sensors in satellites to obtain data. In this sense, the objective of the RaioSat project is to develop national technology for detecting lightning flashes from the space, in order to complement the existing data from the ground detection network, BrasilDAT. The main objective of this article is to present a methodology for the development of the RaioSat mission including some parts of the preliminary design and operational modes. Additionally, the article describes the expected results and the continuity of the project and a preliminary analysis of a constellation for future projects.
\end{abstract}

Keywords: Nanosatellites; Lightning; Atmospheric; Phenomena; Digital cameras; Systems design.

\section{INTRODUCTION}

The detection and geolocation of lightning flashes are important for a wide variety of applications in several areas of scientific research. Some of them are the short-range forecasting systems for the occurrence of severe atmospheric events, identification of damage to structures and definition of protection standards, risk analysis involving deaths and fires, scientific research on

Received: Mar. 02, 2020 | Accepted: Oct. 10, 2020

Peer Review History: This is a peer reviewed version of selected paper presented at the $2^{\circ}$ Congresso Aeroespacial Brasileiro occurred in 16 -19 September of 2019 at Universidade Federal de Santa Maria, Santa Maria/RS, Brazil.

Section Editor: Marcelo Zanetti

This is an open access article distributed under the terms of the Creative Commons license. 
atmospheric phenomena of the terrestrial system, determination of economic and social impacts through insurance claims, electricity interruptions and forensic data. On the other hand, some of the users of lightning flashes information are the universities, research institutes, meteorological agencies, civil aviation companies, military facilities (including air traffic control and spaceports), environmental and natural resource management agencies, natural disaster relief organizations, electric power transmission and distribution operators (Naccarato and Pinto Junior 2012a).

A ground detection system is a network composed by four to five sensors linked to a processing center. The ground detection networks have been in operation since the 1920s. In Brazil, a quasi-continental scale network, composed of more than 60 sensors, called BrasilDAT, was implemented in 2010. Since 2012, the BrasilDAT started to produce reliable data for scientific research and applications. The data is collected from the south-central region of the country. The north and northeast regions (including the entire Amazon) are still without monitoring (Naccarato and Pinto Junior 2012b).

The ground lightning flashes detection networks make it possible to generate accurate data, but require high maintenance costs to ensure that all sensors, or at least most of them, are operating, which, at the same time, requires a good power supply infrastructure, availability of communication channels and multiple installation requirements in the place. The sensors on board of satellites allow a wider coverage, detecting lightning with the same efficiency, and with identical temporal and spatial resolutions. The data obtained by RaioSat sensors will be made available to end users and will complement the information from the BrasilDAT network.

Therefore, there is a strong motivation to improve the forecasting techniques for severe atmospheric events using numerical weather prediction (NWP) models. Several studies published in the scientific literature show that the assimilation of lightning flashes data in high spatial and temporal resolutions models can provide an improved representation of convection at the beginning of the forecast (Fierro et al. 2012, 2014, 2015; Wang et al. 2017; Zhang et al. 2017).

Severe weather phenomena (frontal transient systems, mesoscale convective complexes, tropical cyclones, local convective systems and supercell-like storms) are responsible for tens of thousands of deaths and tens of billions of dollars of damage, reported annually worldwide, according to data published on the internet through the Our World in Data portal (https://ourworldindata. org/natural-disasters). In Brazil, atmospheric conditions that provide the formation of severe weather phenomena require more studies to predict their occurrence with more assertiveness and in a short time (up to $6 \mathrm{~h}$ ), for alerts to be sent to different segments of society to reduce deaths and material losses.

The National Institute for Space Research (INPE) promotes means of technological and scientific development, meeting internal and external demands through project coordination, mission analysis, management, including the execution of the RaioSat project. The institute promotes the synergy between educational and research institutions (national and/or international) according to its mission: produce science and technology in the space areas and the terrestrial environment and offer unique products and services for the benefit of Brazil.

\section{THE RAIOSAT MISSION}

The RaioSat mission is the simultaneous detection of lightning flashes embedded within a cloud, without strike the ground, called intracloud lightning (IC) (Rakov and Uman 2003) and the cloud-to-ground lightnings (CG). The combination of these two information is also known as total lighting.

An atmospheric discharge (lighting flash) is essentially a large impulsive of electric current that occurs in the Earth's troposphere. Lighting flashes are the result of electrification of storm clouds or cumulonimbus and radiate electromagnetic energy over a wide range of frequencies (Naccarato 2005).

The RaioSat mission intends, by the first time, the integration of a sensor in a CubeSat to detect lightning flashes, with the development of national technology to the detection of lightning flashes from space (Julio Filho et al. 2020). The data collected complement existing data from the Brazilian ground detection network (BrasilDAT). The detection of lightning flashes from space 
requires only one instrument with a wide coverage area (Nag et al. 2015), which, at the same time can contribute to increasing the quality of data throughout the national territory at lower costs.

Figure 1 presents a general view of the space mission elements, including the space segment, ground segment and launcher segment.

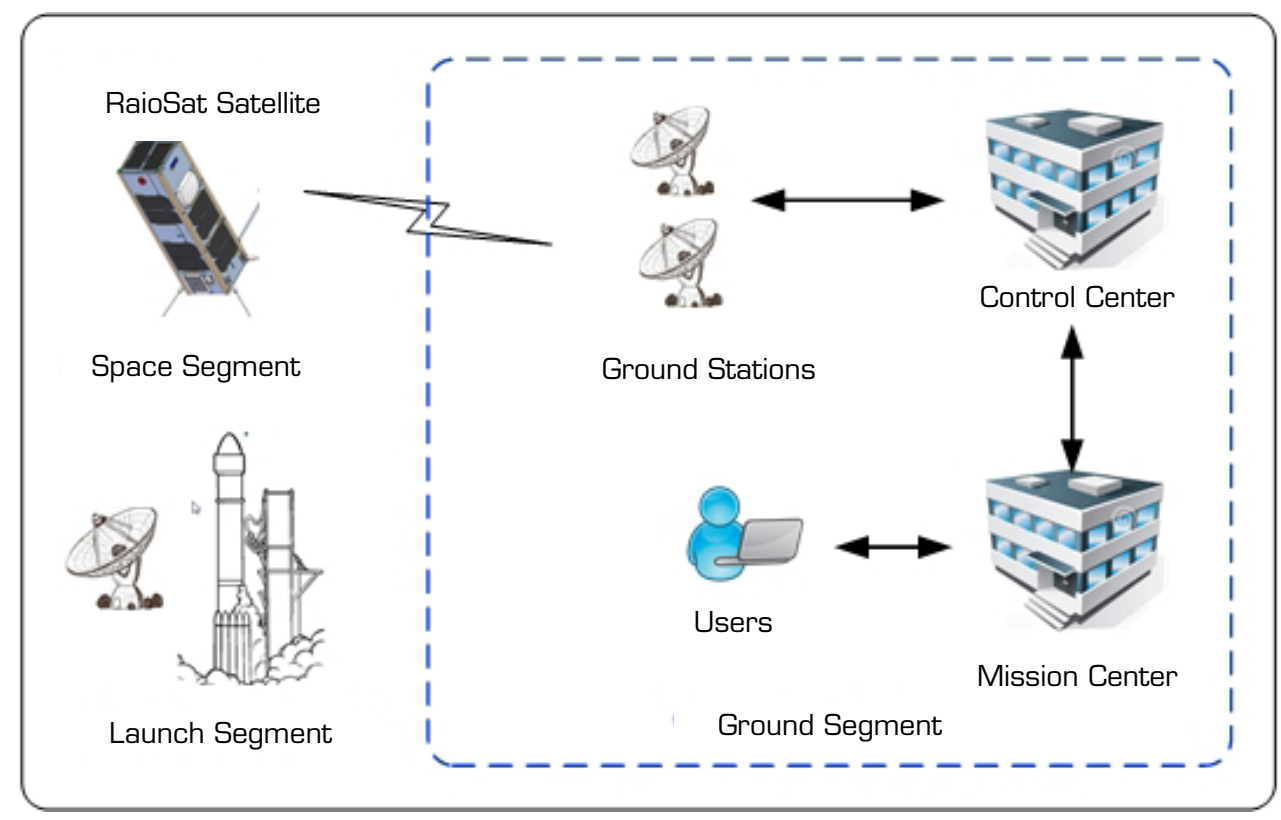

Figure 1. RaioSat space mission elements.

The global mission requirements such as dimensions, mass, power consumption, communications protocols, onboard handling data, attitude determination and control system, pointing precision, orbit and mission lifetime, are presented in Table 1.

The operating mission of the RaioSat is described by the next steps:

- The satellite monitors storms, searching and collecting data from the lighting flashes as part of the global lightning detection mission;

- The data collected from the lightning flashes are transmitted to the image processing system;

- The data is on-board processed to characterize the occurrence of lightning flashes, also is transmitted for analysis at the mission control center;

- The lightning detection algorithm determines the probability of its occurrence in the analyzed location;

- When the lighting flashes are detected and validated, the systems generate a set of data for the researchers which indicate the detection at a specific local and time;

- The users report the lightning flashes statistics and notify the responsible authorities and/or interested researchers. Researchers use the data in applications and provide their results to the end users;

- The system continues to monitor new lightning flashes together with the BrasilDAT network and the area in its vicinity. The operating modes provided for the RaioSat, including the orbital control, the requirements in attitude and pointing, the ON/OFF cycles are presented in Fig. 2. 
Table 1. RaioSat mission global requirements.

\begin{tabular}{|c|c|}
\hline Item & Requirement \\
\hline External dimensions & CubeSat $3 \cup(10 \times 10 \times 30 \mathrm{~cm})$ \\
\hline Maximum total mass & $3 \mathrm{~kg}$ \\
\hline Total power consumption & $6.5 \mathrm{~W}(\mathrm{TBC})$ \\
\hline Frequency range (uplink/downlink) & $430-440 \mathrm{MHz}$ \\
\hline Modulation & AFSK or FSK or GFSK \\
\hline Date rate range & 1200 - 9600 bps \\
\hline Data link layer protocol & AX.25 \\
\hline Total data onboard storage & 4 Giga (TBC) with redundancy \\
\hline Attitude control & 3 axes \\
\hline Pointing precision & From 1 to $5^{\circ}$ (TBC) \\
\hline Camera field of view at cloud level & $10 \mathrm{~km}$ \\
\hline Space resolution & $80 \mathrm{~m} / \mathrm{px}$ \\
\hline Temporal resolution & 500 fps \\
\hline Planned orbit & LEO \\
\hline Orbit altitude & $650 \mathrm{~km}$ \\
\hline Orbit inclination & $70^{\circ}$ (TBC) \\
\hline Mission lifetime & $\begin{array}{l}\text { Around } 6 \text { months (Oct.- Marc), } \\
\text { raining season }\end{array}$ \\
\hline Desired Wavelength & 777.4 nm \\
\hline Camera sensibility & $\begin{array}{l}400-750 \mathrm{~nm} \text { spectral } \\
\text { transmission }\end{array}$ \\
\hline
\end{tabular}

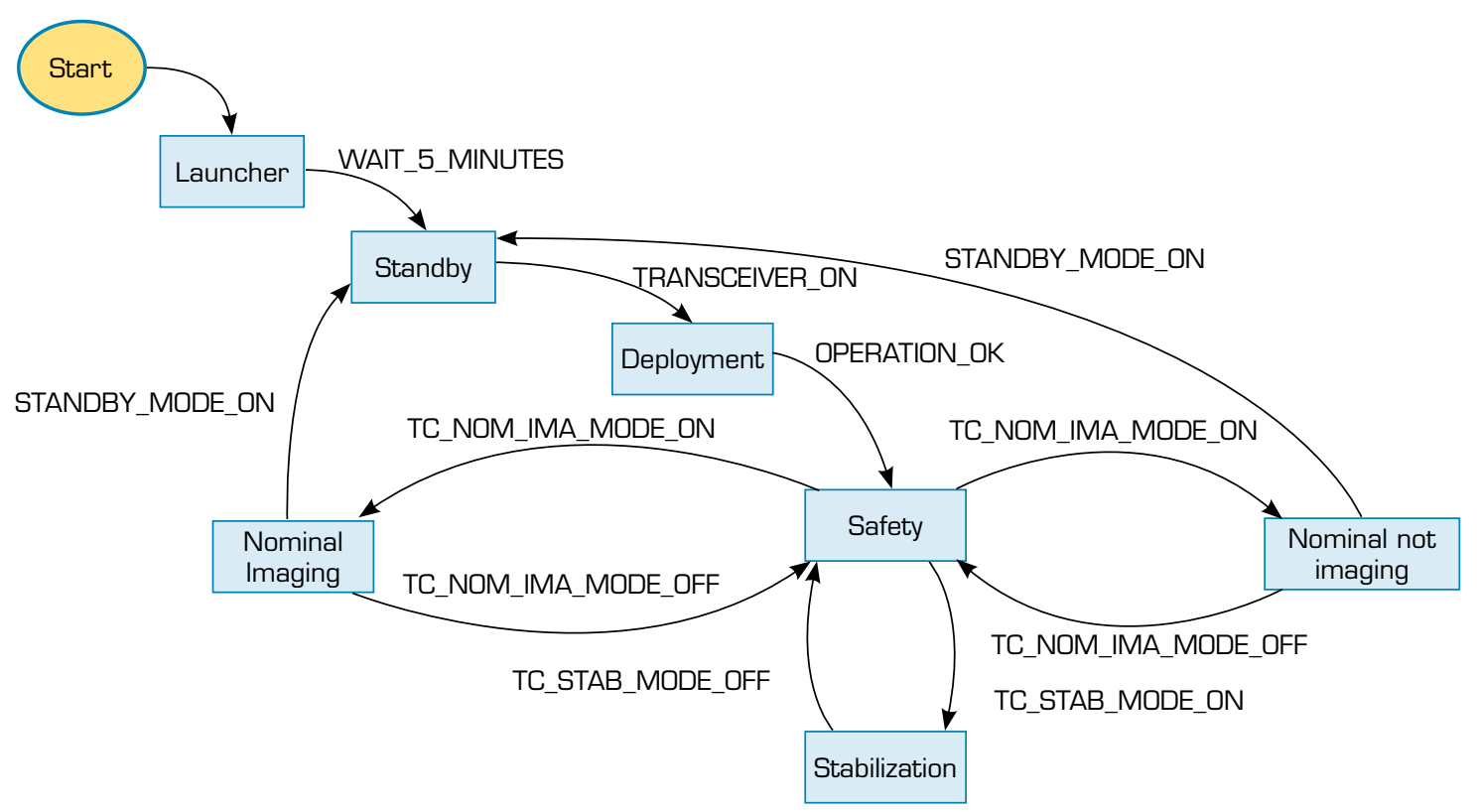

Figure 2. RaioSat operating modes. 


\section{Space Segment}

The RaioSat is projected to be integrated into a $3 \mathrm{U}$-CubeSat structure $(10 \times 10 \times 30 \mathrm{~cm})$, composed by the service module and payload module (Fig. 3). The RaioSat service module will include the communication subsystems, power supply, on-board computer and the 3-axes attitude control (Naccarato et al. 2017). The payload module will be composed by the VHF receiver with passive antenna between 80 to $200 \mathrm{MHz}$; a spectral imaging camera with $2048 \times 1536$ px of resolution (Moura 2017) and a GPS receiver.

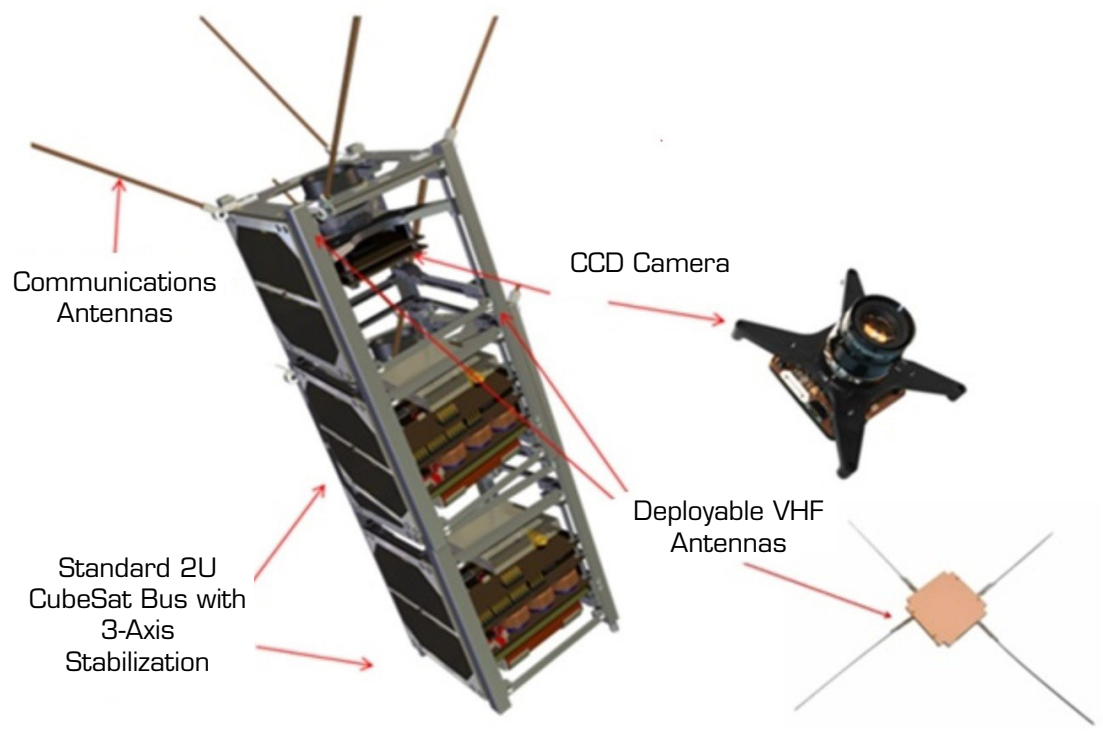

Figure 3. RaioSat, payload and service modules.

Preliminary analysis shows that a good performance orbit for the mission is located at low Earth altitudes (LEO) with quasipolar inclination and lifetime around six months (between October to March, storm season). According to the launcher restrictions, also it is possible to select a different inclination.

\section{Payload module}

The camera to be used must allow a surface image resolution of around $80 \mathrm{~m} / \mathrm{px}$, in the spectral range of 700 to $900 \mathrm{~nm}$, using an optical filter sensor for the bands ionizable oxygen (OI) (777.4 nm) and ionizable nitrogen (NII) (868.7 nm) (Luz 2015). Other sensor specifications: resolution: $2048 \times 1536$ px, image sensor RGB (Bayer) of 10 bits; RAM DDR2: 512 MB; Data storage: 2 GB; Output files BMP, RAW and JPEG; interfaces: CPS-enabled CAN. I2C, RS-422 and TTL.

The payload module must include a VHF receiver (Hamlin et al. 2009) from 80 to $200 \mathrm{MHz}$ to validate the events detected with the sensor on the camera, implementing software defined radio (SDR). Also, a GPS receiver must be included for collected data georeferencing.

A GPS available is the piNAV-L1 from Nano Avionics. The GPS module must have the following characteristics: Operation at LEO (altitude lower than $3600 \mathrm{~km}$ ), mean power consumption around $120 \mathrm{~mW}, 3.3 \mathrm{~V}$ at $25^{\circ} \mathrm{C}$; signal L1 C/A, $15 \mathrm{channels}$ with $1 \mathrm{~Hz}$ of position rate.

\section{Service module}

a) On-board computer

The RaioSat on-board computer will integrate the processor RISC, from the models ARM 9 with 32 bits and $400 \mathrm{MHz}$. The functions that will be executed by the on-board computer are:

- Supervision: Ensure that in case of failure, the contingency actions will be taken;

- Scheduling: Save and execution of the tasks, which were assignment previously using telecommand; 
- Receiver: Perform demodulation and data recovery from telecommands;

- Housekeeping: Collect the performance data of the satellite;

- Log: Generate a record of events;

- Deployment: Extend the moving parts of the system;

- Beacon: Enable the satellite beacon transmission;

- Downlink: Transmit telemetry;

- Payload: Manage the payload activity.

Figure 4 shows the tasks ratio to be development by the on-board computer (OBC), according to the operational modes of the RaioSat.

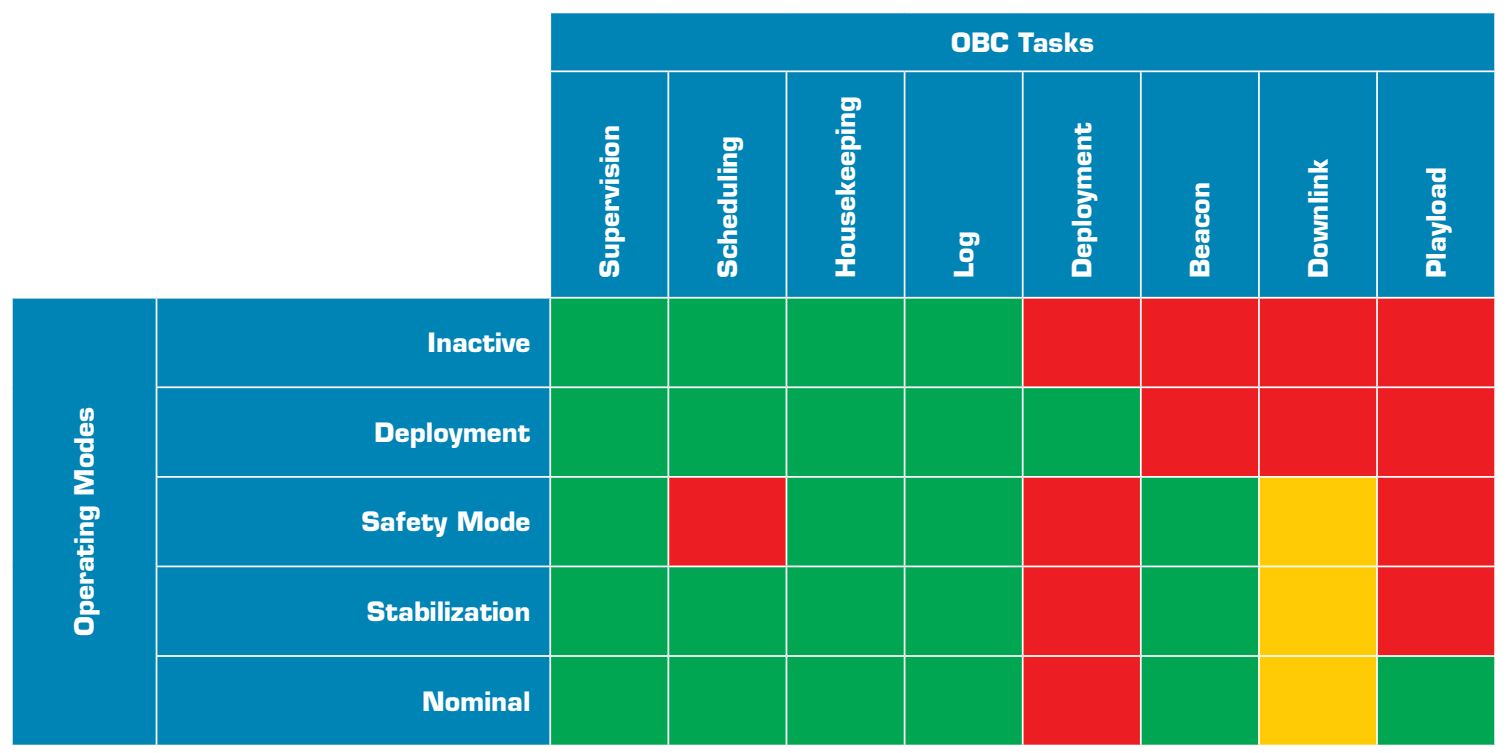

Figure 4. On-board computer tasks.

b) Power supply

The electrical power system (EPS) is responsible for generate, store, control and distribute the electrical energy required for the operation of all subsystems and payload during the mission (Mahdi et al. 2014). The EPS have four functional parts, like is shown in Fig. 5.

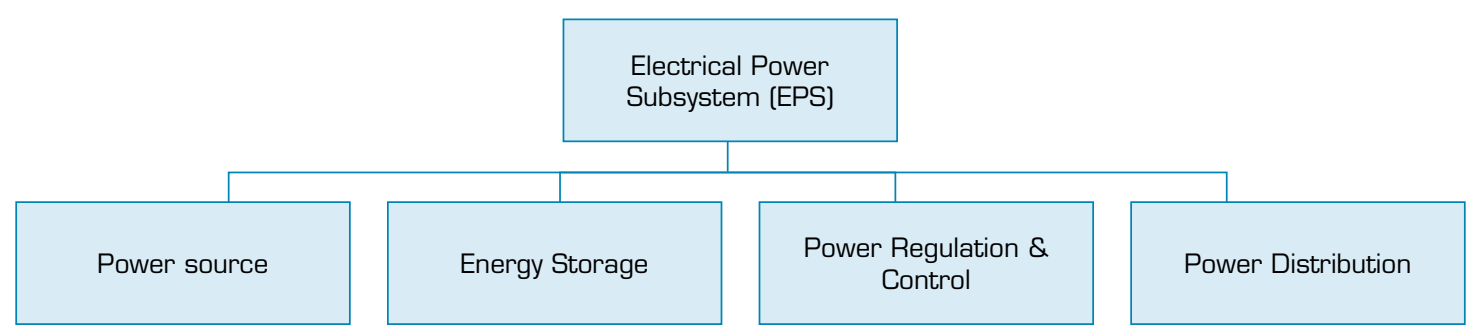

Figure 5. Functional architecture of the EPS (Wertz and Larson 1999).

The first function, power source, is related to the electrical current generating component (solar panel) which in CubeSats, the most common components are the solar photovoltaic cells.

The second function is the form of energy storage to supply peak and subsystems consumption during periods of eclipses. This task is executed by the batteries. 
The third function, power regulation and control, is related to the architecture and method of energy transfer, where O'Sullivan (1989) presented the two main techniques: power peak tracker (PPT) and direct energy transfer (DET), showing the EPS topologies.

The fourth function, power distribution, is related to the delivered of electrical energy to the loads. It is consisting of AC converters and DC regulators.

The EPS design must identify the needs from the beginning to the end of the satellite lifetime, related with the mission requirements. The high-level requirements adopted for the RaioSat EPS (Wertz and Larson 1999) are:

- Provide a continuous source of energy for the loads during the mission lifetime;

- Control and distribute the power;

- Ensure the fulfillment of power consumption needs, including common operations and peak consumption;

- Conversion or energy to AC and regulation of energy to DC (if is necessary);

- Provide the telemetry and the status of the system to determine the performance;

The power balance varies according to the mission. The end-of-life (EOL) energy demands must be reduced in order to compensate for solar panel degradation (Wertz and Larson 1999).

Table 2 presents the estimated power budget for the RaioSat solar panel and EPS components selection. The subsystems showed are OBC; telemetry, tracking and command (TT\&C); attitude control systems (AOCS) and payload.

Table 2. Estimated power budget for the RaioSat mission.

\begin{tabular}{|c|c|c|c|c|}
\hline \multirow{3}{*}{ Subsystem } & \multirow{3}{*}{ Component } & \multicolumn{3}{|c|}{ Operating modes / Power $(\mathrm{mW})$} \\
\hline & & Standby & $\begin{array}{l}\text { Nominal without } \\
\text { imaging }\end{array}$ & $\begin{array}{l}\text { Nominal } \\
\text { Imaging }\end{array}$ \\
\hline & & Power $(\mathrm{mW})$ & Power $(\mathrm{mW})$ & Power $(\mathrm{mW})$ \\
\hline \multirow{3}{*}{ EPS } & Solar Panel & 0 & 0 & 0 \\
\hline & PCDU & 125 & 125 & 125 \\
\hline & Battery & 0 & 0 & 0 \\
\hline $\mathrm{OBC}$ & CPU & 250 & 250 & 250 \\
\hline TT\&C & Antenna UHF & 100 & 1000 & 1000 \\
\hline \multirow{2}{*}{ AOCS } & Magneto torque & 0 & 1300 & 1300 \\
\hline & Reaction wheels & 0 & 2700 & 2700 \\
\hline \multirow{4}{*}{ PAYLOAD } & Camera NanoCam C1U & 0 & 0 & 330 \\
\hline & Sensor PhotoBit PB MV13 & 0 & 500 & 500 \\
\hline & GPS piNAV-L1 & 0 & 120 & 120 \\
\hline & Receiver VHF & 0 & 100 & 100 \\
\hline \multicolumn{2}{|c|}{ Subtotal $(\mathrm{mW})$} & 475 & 6095 & 6425 \\
\hline \multicolumn{2}{|c|}{ Total + margin (20\%) } & & $7710 \mathrm{~mW}$ & \\
\hline
\end{tabular}

It is possible to observe in Table 2 that the power requirement is around $6.5 \mathrm{~W}$ in the nominal mode with imaging. Solar panels should provide this power with a $20 \%$ margin, that is, approximately $7.7 \mathrm{~W}$.

c) Communications

The communications subsystem is responsible for the exchange of information between the satellite and the ground segment, containing two links uplink and downlink, that will operate in the UHF band. The RaioSat operational frequency will be assigned by the International Telecommunication Union (ITU), organization responsible for global radio frequency coordination.

In small satellites, it is advantageous that the communication between satellite and the ground segment occurs in the UHF band (amateur radio band $430-440 \mathrm{MHz}$ ), allowing the reception of data by the amateur radio community. The International Amateur Radio Union (IARU) is responsible for assignation of the frequency for a satellite operating in that UHF range. 
The data rates for the uplink (telecommand) and the downlink (telemetry) are between $1200 \mathrm{bps}$ and $9600 \mathrm{bps}$ with AX.25 protocol. The communication will be carried out via a programmable transceiver, from 430 to $440 \mathrm{MHz}$, with high performance and low consumption. The receiver must have high sensitivity (around $-118 \mathrm{dBm}$ at $9600 \mathrm{bps}$ ) and the transmitter should allow data communication in narrowband channels with modulation to be defined, between AFSK, GFSK, FM and FSK (including G3RUH). d) Attitude control system

The attitude control on satellites is critical when pointing is necessary, for example in cameras pointed towards Earth. It is also fundamental in the alignment of other devices such as solar panels and antennas for spacecraft on different missions.

The pointing precision require for the camera of the RaioSat will be of maximum $5^{\circ}$ with $80 \mathrm{~m} / \mathrm{px}$ of spatial resolution and $10 \mathrm{~km}$ of field of view. The AOCS will use 3-axis stabilization with magnetorquers and reaction wheels.

According to Murcia et al. 2019, the AOCS is implemented so that sensors point to the area of interest during a passage. In addition, it directs the solar panels to the sun. A 3-axis AOCS was selected for the mission, due to the precision required for the sensor pointing. Commercial AOCS or integrated units present TRL higher than 7, like the MAI-401 from Adcole Maryland Aerospace with mass of $560 \mathrm{~g}$, size of $0.5 \mathrm{U}$, including 3 reaction wheels, 3 -axis magnetometer, star tracker and 3 torque rods and precision lower than $0.1^{\circ}$ (NASA 2018). The AOCS maintained the satellite $x$-axis aligned to the flight vector ( $+\mathrm{x}$ face), the $+\mathrm{z}$ face pointing to the nadir with the sensors, the $-\mathrm{z}$ face to the zenith with the solar panels. The angular velocity in the $y$-axis must be maintained constant at $3.71 \%$ min. In the $x$ and $z$ axis, the AOCS must keep the orientation and counteract the torques generated by environmental perturbations.

\section{Product breakdown structure and architecture}

The RaioSat product breakdown structure (PBS) is presented in Fig. 6, where the components of the subsystems are analyzed. The physical architecture is added to the generic physical architecture, detailing the performance characteristics and resource requirements for physical elements. For the creation of the physical architecture, it was necessary to allocate functions to the general architecture, assigning physical interfaces between the components and derivatives requirements for those components of the system requirements. For example, in instantiated physical architecture, the reaction wheels (quantity and capabilities), sensors (type and quantity), magnetometers (quantity and capabilities) were specified.

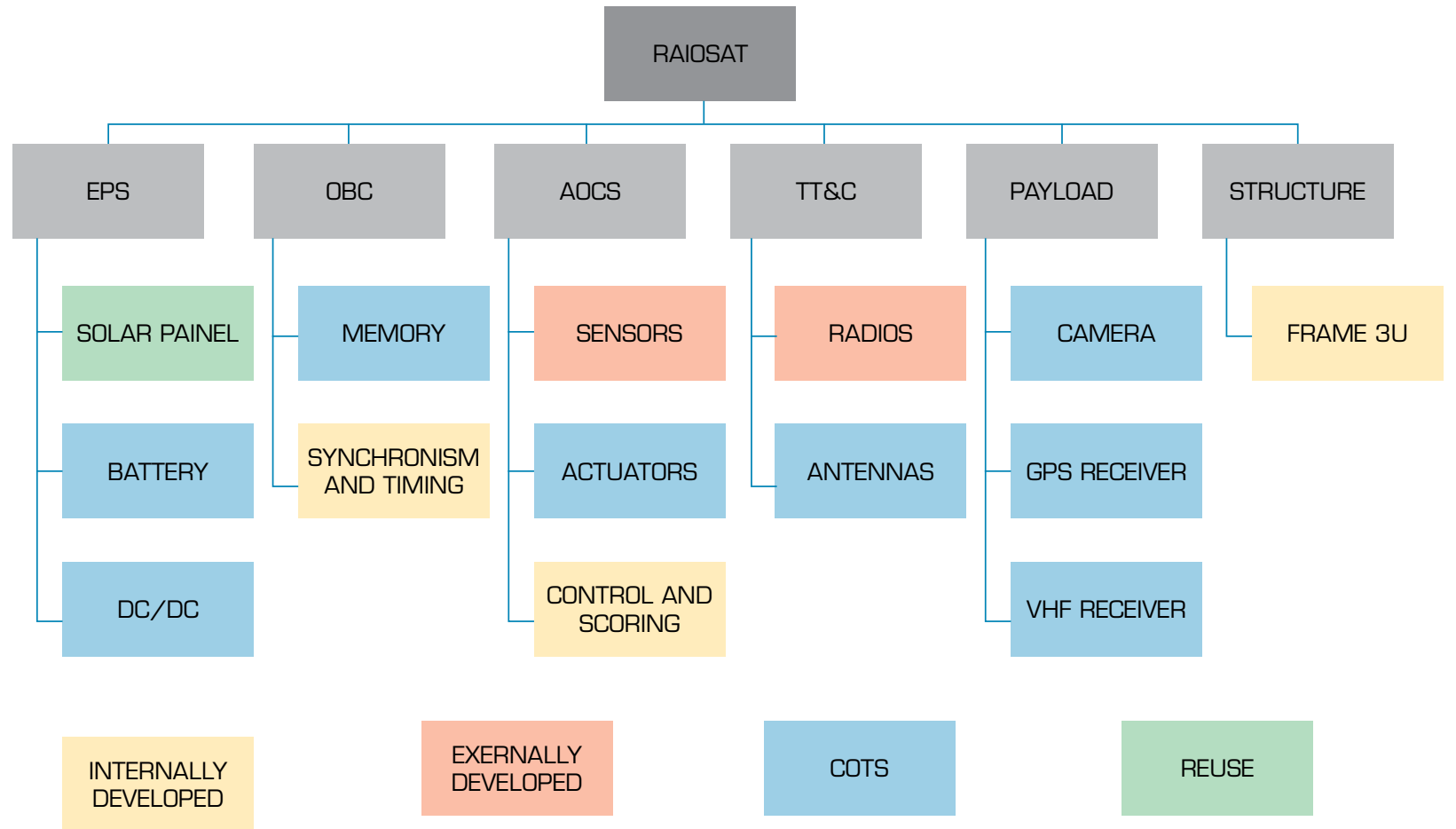

Figure 6. RaioSat Product breakdown structure (Maia et al. 2018). 
The EPS system consists of the solar panel, batteries and the DC/DC converter. The OBC consists of the on-board computer, memory and synchronism module and timers. The AOCS module is formed by sensors, actuators and a control system. The TT\&C module is formed by the transmission and reception modules and antennas. The payload module consists of a VHF receiver and a GPS receiver and finally the structure is the $3 \mathrm{U}$ frame.

The colors of each subsystem indicate the possible solutions for implementation. The green color indicates reuse, the blue color indicates the acquisition of commercial off-the-shelf (COTS), the orange color indicates internal development and the pink color indicates external development by the industry.

The instantiated physical architecture of the RaioSat is presented in Fig. 7. It shows the systems that make up the RaioSat satellite and the respective modules. The modules are the EPS, OBC, AOCS, TT\&C, payload and structure, as presented in the previous sections.

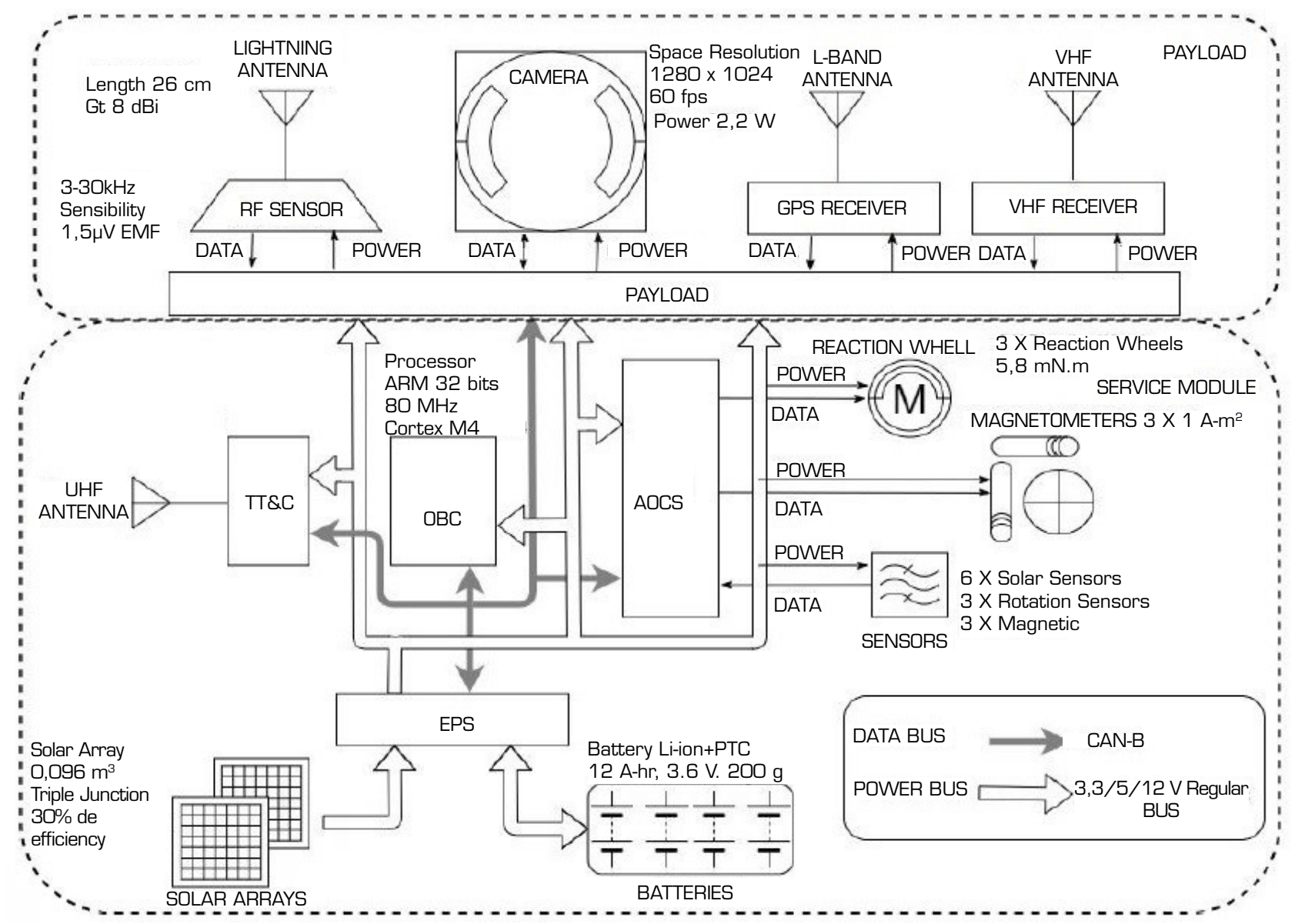

Figure 7. RaioSat physical architecture (adapted from Maia et al. 2018).

\section{Ground Segment}

To allow communication with the satellite, the INPE has two ground stations related to CubeSats and located in the cities of Santa Maria, state of Rio Grande do Sul, and São José dos Campos, state of São Paulo. The ground stations have the following characteristics: VHF/UHF Yagi antennas, low noise amplifier and terminal node controller (TNC) between 1200 - 9600 baud (AX.25 AFSK, FSK and BPSK). In addition to the available ground stations, the data can also be received by amateur radio operators allowing a wide distribution of the data collected. 
The telemetry and payload data will be transferred, via the data network, to the mission operating group and to the Earth Sciences Department at INPE. The RaioSat will collect data from the CG lighting flashes, measuring the intensity, polarity, time and geographic location. The data will be sent to the operational ground station, when a real flash lightning signature is found. The ground station will receive the data to processing and to distribute to the users, using the INPE's website.

\section{Launch Segment}

For the selection of the launch vehicle or launcher, multiple analyses are necessary to determine the altitude, orbit inclination, lifetime and total cost of the launch. Some options, such as launching from the International Space Station (ISS) (restricted to its orbit), are available. In this case, the CubeSats are transported to the ISS in supplement transference vehicles (ex. Cygnus, Dragon and Kounotori) launched from rockets (such as Falcon 9, Antares and HII-B). Other possible space transportation systems are the Russian RS-20 (DNEPR), the Americans launchers Pegasus or Electron and the Brazilian rocket VLM-1.

Besides those launchers, there are several companies that organize launches and indicate the best launcher options for each CubeSat project. For example, the company Innovative Solutions In Space (ISIS), from the Netherlands, and the Spaceflight Industries, from the United States, in charge of the SmallSat Express program.

The quantity of launchers available for an inclination of $70^{\circ}$ is lower than the quantity available for sun synchronous orbit (SSO) around $98^{\circ}$, where the largest quantity of CubeSats, implemented in meteorological or remote sensing missions, is located.

A preliminary analysis of the orbit for the RaioSat mission along five months, between November of 2020 to April of 2021 , maximum solar luminosity (12:00 - 17:00 UTC) with $45^{\circ}$ of sensor field of view (FOV), shows that the number of passages above the Brazilian territory is 144, with average duration of $385 \mathrm{~s}$ and 6.5 days for revisiting.

In the case of the RaioSat in SSO, the number of passages increase to 296 at the same period, with average duration of $403 \mathrm{~s}$ and mean revisiting time of 4.3 days.

The launcher requirements are related to the space qualification requirements, including the mandatory tests and development tests. The mandatory tests must be conducted under the imposition of the responsible for launching the CubeSat (Fernandes 2014).

The development tests are carried out under the demand of the developers in order to ensure the functioning of the subsystems when exposed to the space environment (thermal testing, pressure and electromagnetic interference), or mechanical stresses during transportation (acoustic, vibration, mechanical shock) (Fernandes et al. 2016).

In this case, it will be necessary to use a laboratory qualified for space testing. For the present project, the better option for cost/income is the use of the INPE's Laboratory of Integration and Tests (LIT), due to its location, capabilities and qualification for space systems testing.

\section{EXPECTED RESULTS AND PROJECT CONTINUITY}

The main result of the RaioSat mission is the production of reliable data that will be useful in many areas of scientific research and in the improvement of methodologies for predicting the occurrence of several events, in synergy with other areas of research and development of national technology in the area of lightning flashes detection from space to the improvement of existing technologies in the area of small satellites.

The products that are expected to be generated in this multidisciplinary project include:

- The advance in the knowledge of the anthropogenic effect on the formation and electrification of storms, which includes studies of large urban centers and biomass burning;

- The development of methods for predicting the occurrence of severe atmospheric events using numerical models (weather forecasting and electrification of clouds) together with observational data (meteorological and electrical) from the ground stations or from the satellite;

- Understanding how environmental changes affect (or may affect) the formation and system of storms, and consequently, the lighting flashes in the long-term, particularly in urban environments. 
Once the technology to detect lightning flashes through RaioSat is validated, the implementation of the project in the construction of additional satellites is expected to obtain a constellation of at least 6 units. This constellation will allow the coverage of the entire Brazilian territory, 24 hours a day, 7 days a week, obtaining data of lightning flashes in almost real time with wide coverage, good temporal resolution and efficiency of continuous and homogeneous detection in space and time. The constellation analysis is presented in the next section.

\section{Constellation Preliminary Analysis Considerations}

The orbits determined for the RaioSat constellation are selected to provide continuous monitoring of meteorological phenomena. The requirements established for the design of the constellation are an altitude of $650 \mathrm{~km}$, LEO with low cost for launch. The orbit should provide coverage of the Brazilian territory and passages for communication with INPE's stations, in the cities of São José dos Campos and Santa Maria. During the orbital lifetime, the satellites will not carry out altitude maintenance maneuvers, plane changes and /or decay, because they will not have the propulsion subsystems necessary to develop these maneuvers.

Some challenges of the mission are the increase in launch costs for satellites in different orbital planes, and the total cost of developing the project, which limits the number of satellites and the number of orbits, trying to reduce the quantity of launches.

For those reasons, a constellation of six satellites is proposed and analyzed. One of the objectives of the constellation is to increase the coverage of the monitoring area. The requirements must include ground stations for receiving the data at each passage of the satellites. If optimized, this type of satellite constellation allows increasing the contact times with the satellite and the coverage; however, it would need different orbit plans, which increases the costs and launch times.

\section{Preliminary analysis}

A satellite constellation with six satellites distributed in three orbital planes, with two satellites per plane, was analyzed by Carvalho et al. (2013). This configuration of the constellation presents the highest number of revisits per day with a good number of contacts per day, compared with three other constellations of six satellites with different orbital distributions; however, it requires three different orbital planes with two satellites in each.

A large number of launches increases the cost of the mission and the time between launches should be the shortest, since the satellites in LEO are highly perturbed by atmospheric drag, generating a rapid variation of the orbital elements and changing the coverage and effectiveness of the constellation in a short time (in less than a month).

A constellation in SSO (orbital inclination of $97.98^{\circ}$ ) ensures constant pass under good solar luminosity, while the satellites are monitoring, allowing a maximum of energy for the payload, sensors and data transmission. The SSO presents good launch opportunities, but it also has the largest number of small satellites, is an orbit with a larger number of future space debris (AnzMeador 2015). This constellation is excellent for offering services to other countries, ensuring global monitoring, reducing costs, and launch times. In this scenario, international cooperation is needed to increase the number and distribution of ground stations.

For the RaioSat constellation, a configuration of six satellites in the same orbital plane, with angular distance of $60^{\circ}$ and $30^{\circ}$ of inclination, at $650 \mathrm{~km}$ of altitude, was analyzed. In one day of operations, the constellation shows more than 55 passages over the Brazilian territory, with $100 \%$ of coverage during day and night. The largest gap with ground stations is around $8 \mathrm{~h}$ of duration, when the plane of the orbit is out of range and the satellites are in the maximum latitude, which happens once a day. During the $16 \mathrm{~h}$ of continuous links, the maximum gaps have a mean duration of $10 \mathrm{~min}$. This kind of constellation reduces the launching cost, due to the unique orbital plane, and increases the coverage of a single satellite, allowing $100 \%$ of daily coverage. It is also possible to offer data to other countries located between $-30^{\circ}$ to $30^{\circ}$ of latitude. To reduce the gaps and increase the communication links and reduce the time of data collected between the satellite and ground stations, the implementation of a ground station at north of the country is necessary.

Figure 8 shows the passages of each satellite in one day of operation. This figure presents the number of satellite and the duration of the sensor passing over the Brazilian territory. The horizontal axis presents the link time in seconds or epoch, since the beginning of the propagation. The white region presents the interval of time without coverage, with $8 \mathrm{~h}$ of duration. When the 
inclination of the constellation is lower than $30^{\circ}$, it is possible to increase the quantity of links, but it reduces the effectivity of the coverage (lower than 90\%). The passages and the constellation were simulated with the AGI/STK software.

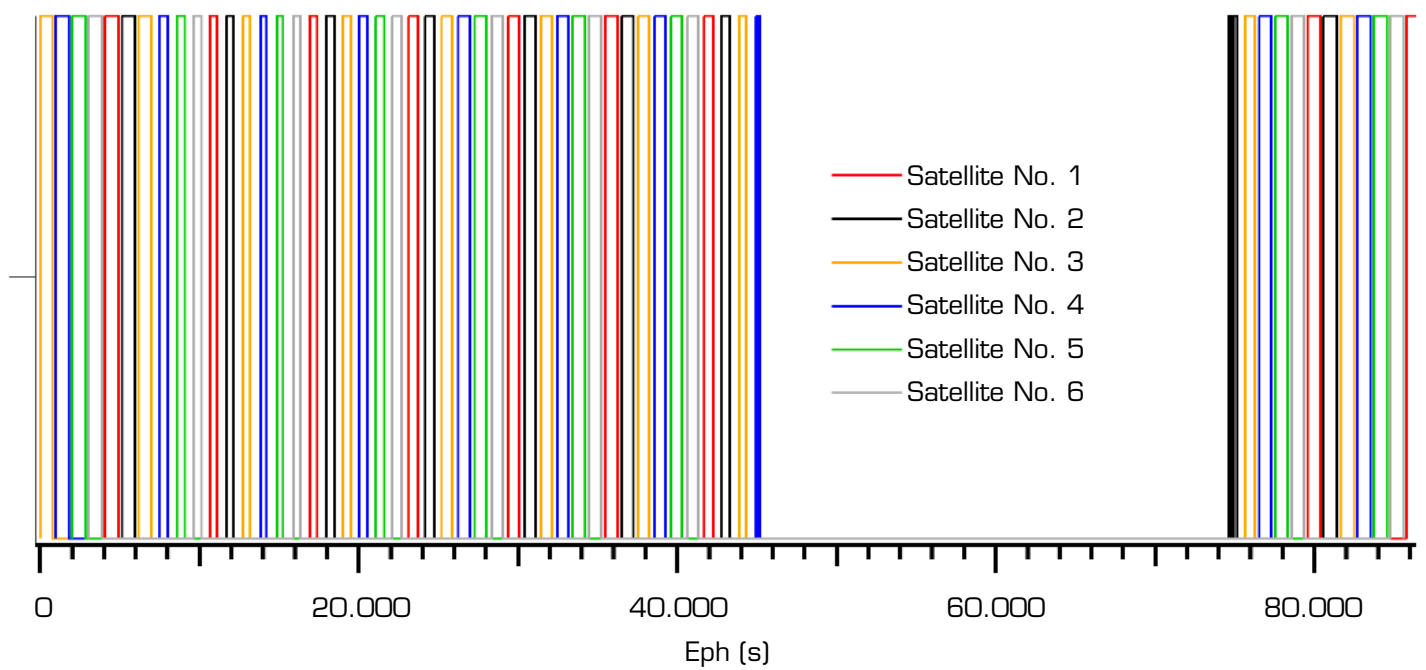

Figure 8. The coverage time for each satellite in one operational day.

\section{CONCLUSION}

Predicting severe thunderstorms with high assertiveness in order to issue precise warnings to different segments of society and, thus, reduce deaths and material losses requires high and accurate lightning data. Then, the uniform detection of lightning flashes for the entire national territory will be an important contribution to the improvement of severe weather phenomena with short-range forecasting (up to $6 \mathrm{~h}$ ).

The main result of the RaioSat mission is the production of reliable data that will be useful in many areas of scientific research and the improvement of forecasting methodologies in occurrence of severe events, in synergy with other areas of INPE.

Besides the production of reliable data, the RaioSat project could promote technological and scientific development with synergy between educational and research institutions, national and international, to: produce science and technology in the space areas and the terrestrial environment and offer products and unique services for the benefit of Brazil.

The most important and innovative technical result of the present work is that the proposed methodology guarantees the integration, for the first time, of a sensor for the detection of lightning flashes in a CubeSat. This paper also presents a preliminary analysis of a CubeSat constellation to increase coverage and offering the services to other countries.

\section{AUTHORS' CONTRIBUTION}

Conceptualization: Julio Filho AC, Tikami A and Santos WA; Investigation: Julio Filho AC, Paula ESF, Piñeros JM and Fernandes GF; Methodology: Julio Filho AC and Paula ESF; Project Administration: Julio Filho AC and Santos WA; Resources: Fernandes GF and Santos WA; Supervision: Santos WA; Formal Analysis: Piñeros JM; Software: Piñeros JM and Camargo LAP; Writing - Original Draft: Julio Filho AC, Tikami A, Paula ESF, Piñeros JM, Fernandes GF, Camargo LAP, Naccarato KP and Santos CAMB 


\section{DATA AVAILABILITY STATEMENT}

All the datasets were generated and analyzed during the current study.

\section{FUNDING}

Coordenação de Aperfeiçoamento de Pessoal de Nível Superior. Grant No: PND-88882.317527/2019-01

http://dx.doi.org/10.13039/501100002322.

\section{ACKNOWLEDGEMENTS}

To the Organization Comittee of II Congresso Aeroespacial Brasileiro and to the Instituto Nacional de Pesquisas Espaciais.

\section{REFERENCES}

Anz-Meador P (2015) A review of space environment implications of CubeSat traffic 2003-2014. Orbital Debris Quarterly News 19(3):4-6.

Carvalho MJM, Lima JSS, Jotha LS, Aquino PS (2013) CONASAT- Constelação de Nano Satélites para Coleta de Dados Ambientais. Paper presented XVI Simpósio Brasileiro de Sensoriamento Remoto - SBSR. INPE; Foz do Iguaçu, Paraná, Brasil.

Fernandes GF (2014) Procedimento de testes vácuo-térmicos, Picosatellite Tancredo I - PFM, Acceptance Level, Program UBATUBASAT, IT01-CUBSAT-TP-001. Private Communication, Issue 1.

Fernandes GF, Santos MB, Silva VD, Almeida JS, Nogueira PRM (2016) Thermal tests for CubeSat in Brazil: lessons learned and the challenges for the future. Paper presented 67th International Astronautical Congress IAC. IAC; Guadalajara, Mexico.

Fierro A, Mansell E, Ziegler C, MacGorman D (2012) Application of a lightning data assimilation technique in the WRFARW model at cloud-resolving scales for the Tornado Outbreak of 24 May 2011. Mon Wea Rev 140(8):2609-2627. https:// doi.org/10.1175/MWR-D-11-00299.1

Fierro AO, Gao J, Ziegler CL, Mansell ER, MacGorman DR, Dembek SR (2014) Evaluation of a cloud-scale lightning data assimilation technique and a 3DVAR method for the analysis and short-term forecast of the 29 June 2012 derecho event. Mon Wea Rev 142(1):183-202. https://doi.org/10.1175/MWR-D-13-00142.1

Fierro AO, Clark AJ, Mansell ER, MacGorman DR, Dembek SR, Ziegler CL (2015). Impact of storm-scale lightning data assimilation on WRF-ARW precipitation forecasts during the 2013 warm season over the contiguous United States. Mon Wea Rev 143(3):757-777. https://doi.org/10.1175/MWR-D-14-00183.1

Hamlin T, Wiens KC, Jacobson AR, Light TEL, Eack KB (2009) Space and ground-based studies of lightning signatures. In: Betz HD, Schumann U, Laroche P, editors. Lightning: Principles, Instruments and Applications: Review of Modern Lightning Research. Springer. p. 641.

Julio Filho AC, Tikami A, Paula ESF, Murcia JO, Fernandes GF, Camargo L, Santos CA, Santos AW, Naccarato K (2019). Development of a CubeSat for detection of atmospheric discharges: RaioSat project. In: Proceedings of the 2nd Brazilian Aerospace Congress. Anais...Santa Maria (RS) Federal University of Santa Maria. [accessed Feb 18 2020]. even3.com.br/anais/2cab2019/224875/ 
Luz ESAM (2015) Estudo de casos de descargas atmosféricas utilizando espectroscopia sem fenda (slitless) (Master Dissertation). São José dos Campos: Instituto Nacional de Pesquisas Espaciais. In Portuguese.

Mahdi MC, Jaafer JS, Shehab A-A-R (2014) Design and Implementation of an Effective Electrical Power System for NanoSatellite. Int J Sci Eng Res 5(5):29-34.

Maia G, Paula E, Pereira M, Camargo L, Naccarato K, Santos W (2018) High-level Developments in Space Systems Engineering of the RaioSat Project. Paper presented 3nd Latin American Cubesat Workshop (LACW). Ubatuba, São Paulo, Brazil. [accessed Feb 10 2019]. http://mtc-m21c.sid.inpe.br:80/rep/sid.inpe.br/mtc-m21c/2020/10.27.11.59

Moura CO (2017) Análise de viabilidade de uma carga útil óptica em nanossatélites para detecção de raios (Master Dissertation). São José dos Campos: Instituto Nacional de Pesquisas Espaciais. In Portuguese.

Murcia JO, Naccarato K, Cardoso M, Tikami A, Julio Filho AC, Fernandes GF, Camargo L, Paula ESF, Santos CA, Batista C. (2019) Preliminary analysis of a nanosat mission to integrate a lightning flashes detector with a biomass sensor in a CubeSat 3U configuration. Paper presented 2nd International Academy of Astronautics Latin American Symposium on Small Satellites: Advanced Technologies and Distributed Systems. INVAP; Buenos Aires, Argentina.

Naccarato K (2005) Análise das características dos relâmpagos na região sudeste do Brasil (PhD thesis). São José dos Campos: Instituto Nacional de Pesquisas Espaciais. In Portuguese.

Naccarato KP, Pinto Junior O (2012a) Lightning warning and Analysis of Lightning Threats Risks for Human Life Protection in Brazil. Paper presented 22nd International Lightning Detection Conference and 4th International Lightning Meteorology Conference. ILMC; Broomfield, Colorado, United States.

Naccarato K. P., Pinto Junior O (2012b) Lightning detection in Southeastern Brazil from the new Brazilian Total Lightning Network (BrasilDAT). Paper presented 2012 International Conference on Lightning Protection (ICLP). IEEE; Vienna, Austria. https://doi.org/10.1109/ICLP.2012.6344294

Naccarato KP, Santos WA, Carrereto MA, Moura C, Tikami A (2016) The RaioSat project: detecting total lightning flashes from a CubeSat. Paper presented 2nd IAA Latin American CubeSat Workshop (LACW). IAA; Florianópolis, Santa Catarina, Brazil.

Nag A, Murphy MJ, Schulz W, Cummins KL (2015). Lightning locating systems: Insights on characteristics and validation techniques. Earth Space Sci 2(4):65-93. https://doi.org/10.1002/2014EA000051

NASA (2018) State of the art small spacecraft technology. California: Ames Research Center, Moffett Field. [accessed Mar 20 2019]. https://www.nasa.gov/sites/default/files/atoms/files/soa2018_final_doc-6.pdf

Rakov VA, Uman MA (2003) Lightning: physics and effects. Cambridge: Cambridge University Press. https://doi.org/10.1017/ CBO9781107340886

O’Sullivan D (1989) Satellite power system topologies. ESA Journal 13(2):77-88.

Wertz JR, Larson W (1999) Space Mission Analysis and Design. Torrance: Microcosm.

Wang H, Liu Y, Cheng WY, Zhao T, Xu M, Liu Y, Shen S, Calhoun KM, Fierro AO (2017) Improving lightning and precipitation prediction of severe convection using lightning data assimilation with NCAR WRF-RTFDDA. J Geophys Res: Atmos 122(22):12-296. https://doi.org/10.1002/2017JD027340

Zhang R, Zhang Y, Xu L, Zheng D, Yao W (2017) Assimilation of total lightning data using the three-dimensional variational method at convection-allowing resolution. J Meteor Res, 31(4):731-746. https://doi.org/10.1007/s13351-017-6133-3 